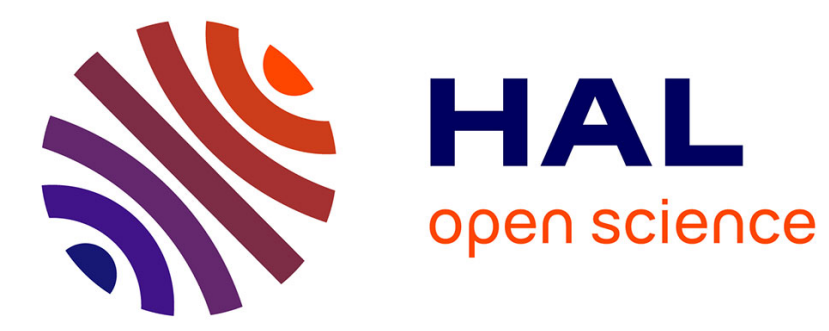

\title{
Efficiency Improvement of a Series-Parallel Hybrid Electric Powertrain by Topology Modification
} Bilal Kabalan, Emmanuel Vinot, Yuan Cheng, Rochdi Trigui, Clément Dumand, Taha El-Hajji

\section{To cite this version:}

Bilal Kabalan, Emmanuel Vinot, Yuan Cheng, Rochdi Trigui, Clément Dumand, et al.. Efficiency Improvement of a Series-Parallel Hybrid Electric Powertrain by Topology Modification. IEEE Transactions on Vehicular Technology, 2019, 10.1109/TVT.2019.2952190 . hal-02403978

\section{HAL Id: hal-02403978 https://hal.science/hal-02403978}

Submitted on 11 Dec 2019

HAL is a multi-disciplinary open access archive for the deposit and dissemination of scientific research documents, whether they are published or not. The documents may come from teaching and research institutions in France or abroad, or from public or private research centers.
L'archive ouverte pluridisciplinaire HAL, est destinée au dépôt et à la diffusion de documents scientifiques de niveau recherche, publiés ou non, émanant des établissements d'enseignement et de recherche français ou étrangers, des laboratoires publics ou privés. 


\title{
Efficiency Improvement of a Series-Parallel Hybrid Electric Powertrain by Topology Modification
}

\author{
B. Kabalan, E. Vinot, Y. Cheng, R. Trigui, C. Dumand, and T. El Hajji
}

\begin{abstract}
Among Series-Parallel Hybrid Electric Vehicle (SPHEV) powertrains, the Power-Split architecture with a planetary gear has an exemplary energetic efficiency in mixed driving conditions. Nevertheless, a simple SPHEV architecture can be realized without a planetary gear. It consists of 2 Electric Machines (EM) mounted on the engine shaft and separated by a clutch. With no power-split operation, this architecture allows the vehicle to operate in pure electric, or series hybrid, or parallel hybrid mode. It was proven to be less efficient than a reference Power-Split SPHEV: the Toyota Hybrid System (THS). The aim of this paper is to investigate the potential of efficiency improvement of the simple SPHEV powertrain by topology modification: the addition of gears for the components or a gearbox with few number of ratios. Two new variants of SPHEVs are proposed. The versions of SPHEVs and the reference THS are optimized by a bi-level optimization technique using Genetic Algorithm and Dynamic Programming. Compared to the simple SPHEV, results show an efficiency worsening in one variant and an efficiency improvement in another variant with a fuel consumption comparable to the one of THS. A global sensitivity study is then performed on the worsened variant. The sensitivities of the added gears are determined and an elimination of some is suggested. A new variant with fewer gears is therefore proposed and optimized. The efficiency is improved but remains less than the one of THS.
\end{abstract}

Index Terms - Dynamic programming, Genetic algorithms, Hybrid Electric Vehicles, Optimization, Powertrain Design.

\section{INTRODUCTION}

$\mathrm{T}$ HE automotive sector is ongoing important transformations. For instance, the move in the course of vehicle hybridization and electrification is widely seen in the announced strategic plans of car manufacturers [1], [2], [3]. This move is driven by a need to meet the fleet average $\mathrm{CO}_{2}$ targets (EU objective of $37.5 \%$ reduction in 2030 compared to

Copyright (c) 2015 IEEE. Personal use of this material is permitted. However, permission to use this material for any other purposes must be obtained from the IEEE by sending a request to pubs-permissions@ @ieee.org.

This paper was submitted for review on August 20, 2019. This work was part of a PhD between IFSTTAR and Groupe PSA.

B. Kabalan (e-mail: bilal.kabalan@mpsa.com) is with IFSTTAR / AME / ECO7, 25 Av. Francois Mitterrand, 69675 Bron, France and Groupe PSA, Centre Technique Vélizy A, case courrier VV1415, Route de Gizy, 78943 Vélizy-Villacoublay Cedex, France.

E. Vinot (e-mail: emmanuel.vinot@ifsttar.fr) and R. Trigui (e- mail: rochdi.trigui@ifsttar.fr) are with IFSTTAR / AME / ECO7, 25 Av. Francois Mitterrand, 69675 Bron, France.

Y. Cheng (e-mail: yuan.cheng@mpsa.com) and C. Dumand (e-mail: clement.dumand@mpsa.com) are with Groupe PSA, Centre Technique Vélizy A, case courrier VV1415, Route de Gizy, 78943 Vélizy-Villacoublay Cedex, France.

T. El Hajji (e-mail: taha.elhajji@gmail.com) is with Groupe PSA.
2021 [4] for passenger cars), the stringent pollutant emissions standards, and the clients' new demands.

Different challenges come with the proposed electrified powertrains. Battery Electric Vehicles (BEVs) have a relatively simple powertrain, but their main challenge is on the battery side (autonomy, charging time, cost...). Hybrid Electric Vehicles (HEVs) and Plug-in (PHEVs) are challenged by the complexity, cost, and control of the powertrain and the complexity of its design. In the following, (P)HEV will be used to refer to HEV and PHEV.

\section{A. (P)HEV design problem}

(P)HEV powertrains combine a battery electric traction system with a conventional engine-based traction system. The two systems can be connected through different means, resulting in various $(\mathrm{P}) \mathrm{HEV}$ powertrain architectures. Series, parallel and series-parallel (power-split and non-power-split) are the main categories of existing hybrid architectures [5].

Once the architecture is chosen, different components technologies can be selected, and different sizing can be made (battery size, components power, gear ratios). The powertrain operation and fuel consumption on a selected driving cycle will depend on the architecture chosen, on the components chosen, on their sizing, and lastly on the energy management during the vehicle operation.

In view of this, the (P)HEV powertrain is an intricate system whose design complexity is linked to the numerous variables that need to be fixed. This can be seen as a multi-objective optimization problem that is spread over multiple levels [6], [7]. The involved variables can be divided into 3 levels (Fig. 1): (1) Architecture level, (2) Components technology and sizing level, (3) Control level.

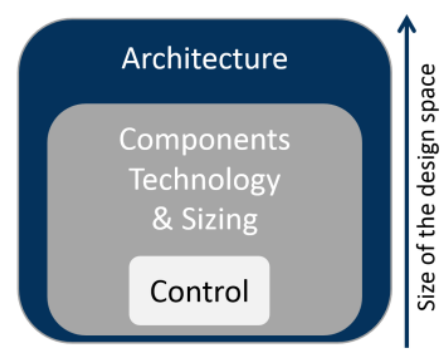

Fig. 1. (P)HEV powertrain design space

The choice of those variables is done taking into account different criteria related to the vehicle requirements: 
performance, fuel consumption, emissions, all-electric range (AER), components lifetime, powertrain cost, powertrain volume, compactness, and other criteria. Some of those criteria are constraints to respect, while others are objectives to optimize.

Various works are done in the literature in the context of this (P)HEV optimization. They tackle the optimization on level (2) and (3) with less efforts on including the level of architecture in the optimization: few benchmark architectures are selected, optimized on the two levels (2) and (3), and then compared. For example, in [8] a topology optimization is presented and three parallel hybrid topologies are compared while varying the transmission technology and the component sizing.

However, the design space on the architecture level has not been entirely screened yet. This is because listing and modelling all the architectures manually is infeasible. In addition, it is because of the model complexity and computation time burden associated with the architectures evaluation and optimization, in case of exhaustive search. Nevertheless, few works started to propose architecture modifications [9], while others started to perform some automatic generation of architectures, in a way to discover a wider part of the architecture level instead of sticking to the few benchmark architectures [10], [11]. In [12] a systematic design methodology is proposed. It generates and compares powersplit architectures with two planetary gears.

\section{B. SPHEV architectures}

According to [13], series-parallel architectures (SPHEV) benefit from the advantages of series and parallel, but they have relatively a more expensive design and complicated control. The most common SPHEV powertrain is the power-split SPHEV that uses a Planetary Gear (PG) as a power-split unit. The Toyota Prius was the first adopter of this architecture in the Toyota Hybrid System (THS) [14], (Fig. 2). Chevrolet Volt and Opel Ampera also adopted the power-split architecture [15].

In power-split SPHEV, the PG decouples the Internal Combustion Engine (ICE) speed from the wheels speed, allowing a speed degree of freedom (DoF), in addition to the torque DoF that is present in any parallel architecture. This helps in moving the operating points of the ICE on its high efficiency area. The cost of this double freedom is that the power going to the wheels is always split between a parallel path and a series path, the latter having a lower efficiency due to the added energy conversion stages. Still, power-split SPHEV remain ones of the most efficient mass produced HEV [16], [8] and the THS is widely used as a reference powertrain.

Nevertheless, other SPHEVs can be realized without a planetary gear system [18]. A simple SPHEV powertrain with no PG was studied in [19] (Fig. 3). It consists of 2 Electric Machines (EM) mounted on the ICE shaft and separated by a clutch. It is relatively a simple architecture that allows vehicle operation in pure electric, series hybrid or parallel hybrid mode. The switching between the modes is done through clutch engaging or disengaging. In contrast to power-split SPHEV, the powertrain does not operate in power-split between series and parallel modes. Its advantage is the possibility to operate in pure parallel mode, avoiding the losses of the series path. Its disadvantage is that the speed DoF is only available in the series mode. It is then more difficult to operate the system in its best efficiency areas compared to power-split SPHEV. In fact, the vehicle speed and torque demands might constraint the powertrain to operate sometimes in series mode even when it has relatively low efficiency. This simple SPHEV architecture has thus been proven to be less efficient than the power-split SPHEV [16].

\section{Contribution and outline}

This paper is concerned with discovering a wider part of the architecture level. This is done by proposing some topology modifications, optimizing the topologies and comparing between them. In the scope of this paper, the comparison is done based on the fuel consumption and the battery size. Instead of considering parallel hybrid topologies with conventional transmissions as in [8] or power-split architectures as in [12], series-parallel topologies with simple transmission are considered here because this paper is part of a global work that is trying to search for new simple and efficient hybrid architectures.

The objective of this paper is to investigate the potential of improvement of the simple SPHEV powertrain by topology modification, in the aim of discovering new simple and efficient hybrid architectures. The paper starts by presenting the simplest version of SPHEV and two proposed variants with added gears or gearbox. The three versions of SPHEVs and the reference THS are then optimized using a sizing and control bi-level optimization methodology. Section II of this paper explains the methodology used to perform this optimization. Section III presents the results of this comparison. Then in section IV, a sensitivity analysis is conducted on the proposed architecture which has added gears. Based on this analysis, the sensitivities of added gears are determined and an elimination of some is suggested. A new architecture is therefore proposed. It will be optimized and compared to the other architectures in section V, using the same methodology.

\section{Methodology}

In this section, the chosen architectures are first introduced. The system modelling is then described. Finally, the methodology used to optimize the sizing and control of the powertrains is presented.

\section{A. Choice of architectures}

The simplest SPHEV architecture is presented in Fig. 3 and will be referred to as SPHEV 1 in the rest of the paper. It was studied in [19] and [20]. The ICE and the EMs are on the same shaft, separated by clutches. Table I lists the operating modes of the powertrain in function of the clutches state. 


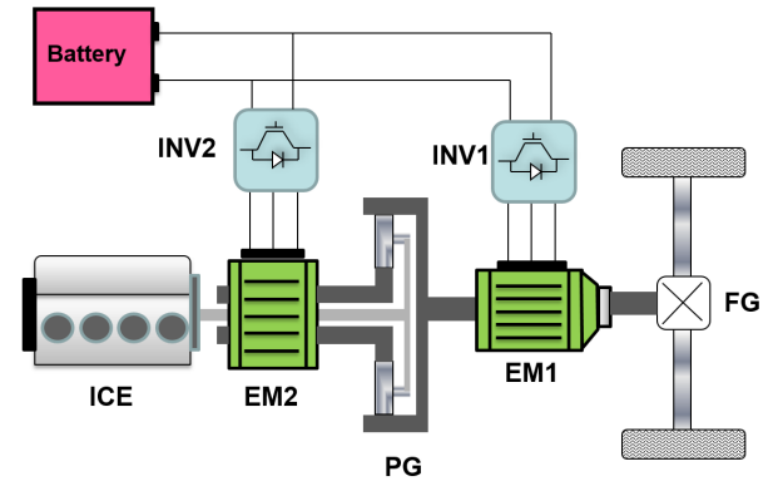

Fig. 2. THS

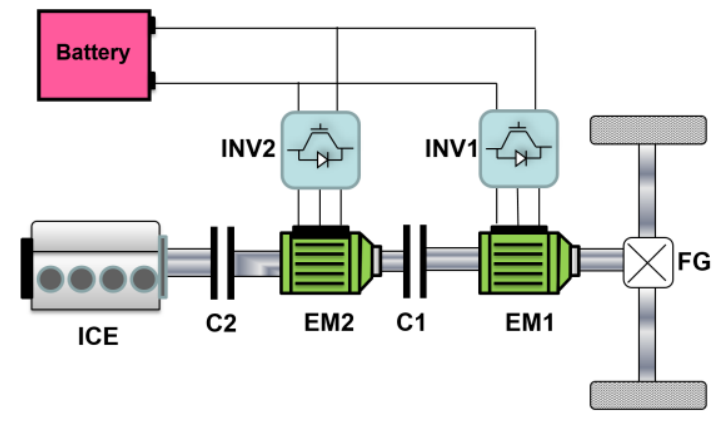

Fig. 3. SPHEV 1

TABLE I

CLUTCHES STATE AND CORRESPONDING OPERATING MODE FOR SPHEV 1

\begin{tabular}{|c|c|c|c|c|}
\hline $\mathrm{C} 2$ & C1 & $\begin{array}{l}\text { Operating } \\
\text { mode }\end{array}$ & $\begin{array}{c}\text { Involved } \\
\text { Components }\end{array}$ & DoF \\
\hline Disengaged & Disengaged & $\begin{array}{l}\text { Electric } \\
\text { mode } 1\end{array}$ & EM1 & 0 \\
\hline Disengaged & Engaged & $\begin{array}{l}\text { Electric } \\
\text { mode } 2\end{array}$ & $\begin{array}{l}\text { EM1, } \\
\text { EM2 }\end{array}$ & $\begin{array}{c}\text { power sharing } \\
\text { variable }\end{array}$ \\
\hline Engaged & Engaged & $\begin{array}{c}\text { Parallel } \\
\text { hybrid } \\
\text { mode }\end{array}$ & $\begin{array}{c}\text { EM1, } \\
\text { EM2, } \\
\text { ICE }\end{array}$ & $\begin{array}{l}\text { power sharing } \\
\text { variables }\end{array}$ \\
\hline Engaged & Disengaged & $\begin{array}{c}\text { Series } \\
\text { hybrid } \\
\text { mode }\end{array}$ & $\begin{array}{c}\text { EM1, } \\
\text { EM2, } \\
\text { ICE }\end{array}$ & $\begin{array}{c}\text { 1-Pbat } \\
\text { 2-ICE speed }\end{array}$ \\
\hline
\end{tabular}

To improve the powertrain efficiency, some topology modifications can be considered: adding a gear between the final shaft and each component (ICE and 2EM), or adding a gearbox to the powertrain, with different possible number of gears and different possible locations. As a first step, the following 2 new variants of SPHEV are proposed:

- SPHEV 2: a SPHEV with one added gear between the final shaft and each component (Fig. 4).

- SPHEV 3: a SPHEV with a gear on each EM and a 2speed gearbox between the 2 EMs (Fig. 5). SPHEV 3 has the same functionality of an architecture proposed by Denso Corporation in [21].
SPHEV 2 has the same operating modes and corresponding DoF as SPHEV 1 (Table I). SPHEV 3 has same modes; however a gear selection DoF is added for the electric mode 2 and the parallel hybrid mode. The number of gears in the gearbox of SPHEV 3 is chosen to be two and is not optimized in this work.

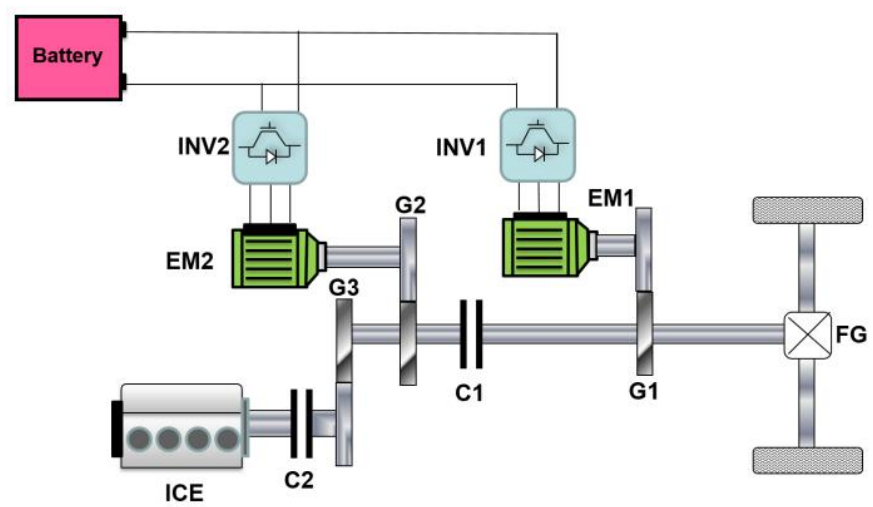

Fig. 4. SPHEV 2

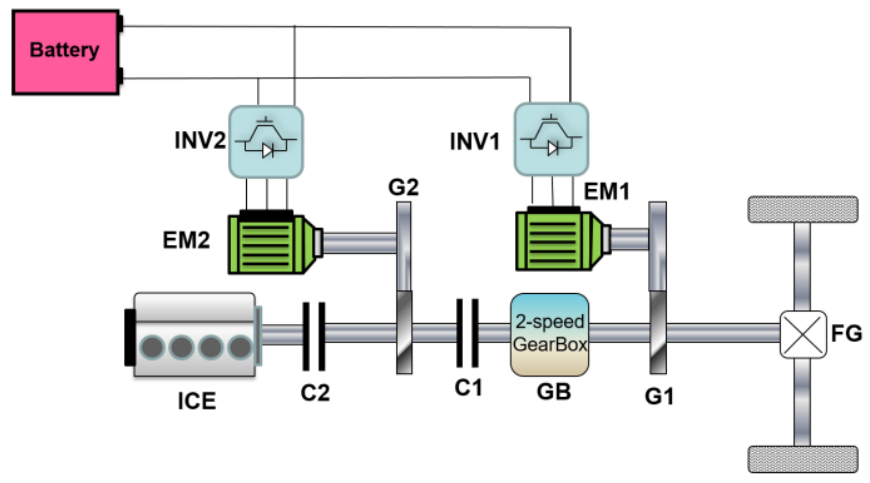

Fig. 5. SPHEV 3

\section{B. System modelling}

In order to assess the different powertrains, the vehicle in its environment needs to be modelled. Energetic models are thus developed on MATLAB using the VEHLIB [22] library of vehicle components and the longitudinal dynamics law. The backward approach is used to calculate the fuel consumption, while the forward approach is used to calculate the vehicle performance.

Concerning the component models, experimental BrakeSpecific Fuel Consumption (BSFC) maps are used for the engine. The electric machines and their converters are modelled using losses maps. The losses of the EMs are generated from reluctance network models (at $500 \mathrm{~V}$ ) that were validated by a finite element model [23] and experimental data [24]. The losses of the inverters are calculated using an analytical model based on inverter parameters (switching losses, switching frequency, recovery charge,...). The global losses (EMs + inverters) will be considered to be independent from the battery 
voltage. A classical equivalent electric circuit model is used for the battery which is considered to be modules in series, for simplicity reason. The choice of series or parallel configuration for the battery modules will not affect the converters and EMs losses. Gear losses are modelled by assigning a constant efficiency to each gear. The sizing of the components is not fixed and will be optimized.

The sizing variables involved are:

- the maximum power of the ICE, of EM1 and of EM2

- the number of battery modules in series

- the ratios of the gears, if existing

- the ratios of the gearbox, if existing

When the sizing variables are chosen by the sizing optimizer, the component characteristics are updated. A scaling technique is done for the ICE and EMs. The scaling factor is the ratio between the sized power and a reference power. The maximum torque curves, the fuel consumption, the power losses maps, and the weight are multiplied by this factor. The inertia is multiplied by this factor to the power $5 / 3$. For the EMs, the thermal boundaries and the geometry was not considered here but was considered in [25]. Concerning the battery, the sizing is performed by changing the number of cells in series. The voltage, maximum power, stored energy and weight are recomputed. The influence of the battery voltage on the EM and converters losses is neglected. For the gears, their ratios are replaced by their sized values, without changing their efficiency.

The vehicle models have also some control variables that needs to be decided during the vehicle operation. They will be presented in the following (Table II).

\section{Optimization process}

To guarantee a fair comparison between the architectures, an optimization process is performed beforehand for each of them to ensure that they are compared based on their optimal potential.

As explained before, the vehicle model has sizing variables that needs to be decided when the powertrain is being designed, and control variables that needs to be decided instantaneously when the powertrain is being operated. A bi-level optimization process is adopted [20], [26], [16]: an upper level sizing optimization for the designing phase and a lower level control optimization for the operation (Fig. 6). This process yields to a Pareto front presenting the tradeoff between the objective functions.

\section{1) Upper level sizing optimization}

The optimization variables on this level are the sizing variables listed in the previous subsection. The architectures can have up to 9 sizing variables; therefore the design space of this optimization can have up to 9 dimensions. The genetic algorithm (GA) NSGA-II [27] is used as the optimization algorithm. GA performs the exploration of this design space

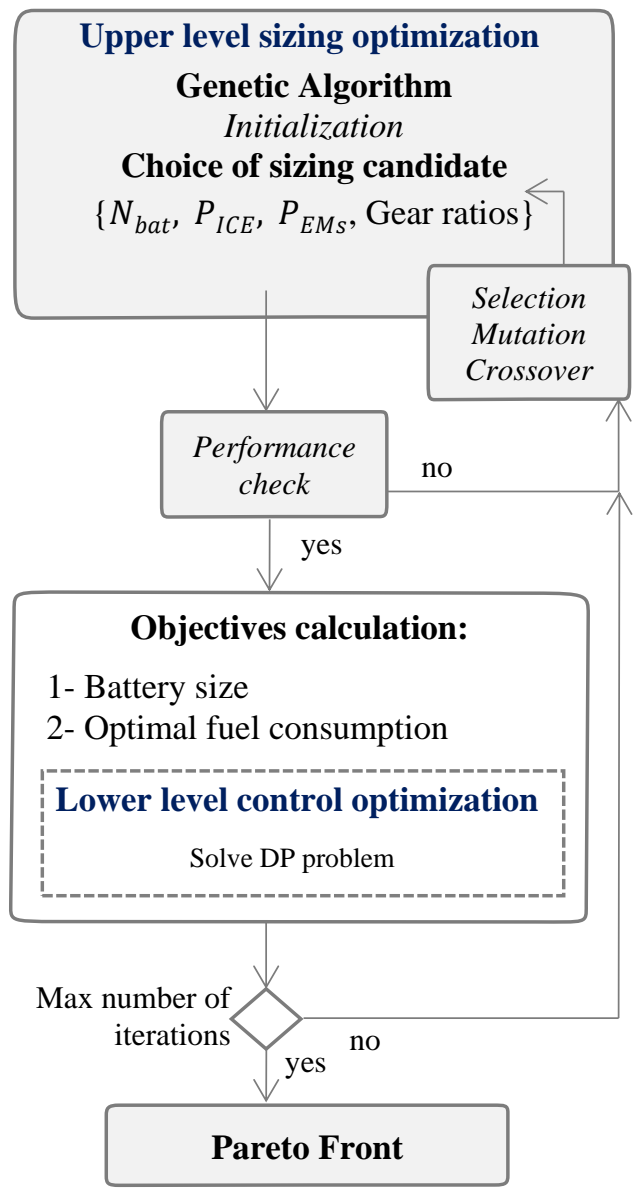

Fig. 6. Optimization process

and generates at the end of the optimization the optimal tradeoff (Pareto fronts) between the objective functions.

The algorithm chooses at each step the sizing candidates to be assessed (set of values for the sizing variables). GA initializes a random population of sizing candidates. After an evaluation of the objective functions of this population, GA performs an evolution process (Selection, Crossover, and Mutation) to produce better generations. For each generated individual, the performance constraint is checked. If it is respected, the objectives are assessed. In this paper, two objectives are considered: the charge sustaining fuel consumption calculated using lower level optimization (DP), and the number of battery modules in series. The latter is an indicator of the battery stored energy and is one of the sizing variables, it does not need to be calculated again. This objective function was selected because it reflects the amount of electrification. It has an influence on the energy management and thus the fuel consumption. A high battery size leads to reduction in fuel consumption because the powertrain can recuperate more energy when needed and has more energy freedom when choosing between electric and hybrid modes. In addition the importance of the architecture on the fuel consumption might decrease when the battery size is big. The process is repeated until a maximum number of iterations is reached. More explanations can be found in [27]. In previous works, the Pareto fronts were compared from 200 to 1000 
generations for different optimizations. No change in the Pareto was seen after 500 generations.

In the performance check, a test is performed to ensure that the sizing candidate respects the following constraints:

- the acceleration time from 0 to $100 \mathrm{~km} / \mathrm{h}$ : $t_{0 \rightarrow 100}<10.1 \mathrm{~s}$

- Acceleration time from 80 to $120 \mathrm{~km} / \mathrm{h}$ : $t_{80->120}<7.5 \mathrm{~s}$

- the maximum speed of the vehicle on a flat road: $V_{\max }>179 \mathrm{~km} / \mathrm{h}$

This performance test is done in hybrid operation. The powertrain choses the mode that maximizes the torque on the wheels (series or parallel). For the parallel mode clutch slipping is allowed when the engine speed is below a threshold value which is higher than the idle speed. If a GB is involved, gear upshifting is performed when one of the upstream components reaches its shifting speed. The latter is the speed corresponding to the maximum power of the ICE or EMs. At the vehicle maximum speed in the performance test, the battery power is not obliged to be null. However any candidate relying on the battery power at high speeds will not be able to finish the driving cycle used for the fuel consumption calculation because of its long highway part, and will be normally dismissed at later stage. Such constraint can be added in future work.

To calculate the fuel consumption, the vehicle is run on a driving cycle. Here, a control optimization problem arises.

\section{2) Lower level control optimization}

The fuel consumption at the end of the cycle is strongly dependent on the instantaneous choice of control variables during the entire vehicle operation. For the 3 proposed SPHEVs, the first control variable is the choice of operating mode. In fact, a given speed and power demand of the vehicle can be accomplished by the powertrain through 4 possible operating modes (electric mode 1, electric mode 2, series hybrid and parallel hybrid). When the gearbox is involved, a control variable of gear selection is added. Specific control variables also exist for each mode, except for electric mode 1. They are listed in Table II.

TABLE II

State AND CONTROL VARIABles Per ARChitecture

\begin{tabular}{|c|c|c|c|c|}
\hline & $\begin{array}{c}\text { State } \\
\text { variable }\end{array}$ & \multicolumn{3}{|c|}{ Control variables } \\
\hline $\begin{array}{l}\text { SPHEV } 1 \\
\text { and } \\
\text { SPHEV } 2\end{array}$ & SOC & $\begin{array}{l}\text { Mode } \\
\text { choice }\end{array}$ & & $\begin{array}{l}* 1 \text { power sharing variable } \\
\text { between EM1 and EM2 in } \\
\text { electric mode } 2 \\
* 2 \text { power sharing variables } \\
\text { between ICE, EM1 and EM2 } \\
\text { in parallel hybrid } \\
* \text { Pbat and ICE speed in series } \\
\text { hybrid }\end{array}$ \\
\hline SPHEV 3 & SOC & $\begin{array}{l}\text { Mode } \\
\text { choice }\end{array}$ & $\begin{array}{l}\text { Gear } \\
\text { choice }\end{array}$ & + Same as above \\
\hline THS & SOC & & Pbat and & [CE speed \\
\hline
\end{tabular}

For the electric mode 2 and the parallel hybrid mode, the control variables are the power sharing between the involved components. In the series mode, the control variables are the battery power and the speed of ICE. For a given battery power and a given power in propelling EM, the engine speed that optimizes the ICE-EM2 system is predetermined before the vehicle simulation. For the THS, the control variables are the battery power and the speed of ICE. At each time step the battery power is discretized; and for each battery power, the engine speed is discretized and the value that maximizes the powertrain efficiency is chosen. A time step of 1 second is used, the SOC is discretized with around 1000 points between $20 \%$ and $80 \%$, and the ICE speed discretization step is $5 \mathrm{rad} / \mathrm{s}$. More details can be found in [28].

This control problem can be solved by different methods, or Energy Management Strategies (EMS). They differ in their optimality, computation time and ability to be implemented or not in real time vehicle operation. In this work, the chosen EMS is the Dynamic Programming (DP) which guarantees the global optimal fuel consumption of each candidate on the entire cycle [29], [30], [31]. The choice of DP implies that the architectures are compared based on their optimal potential of fuel saving and preserves consequently the fairness of comparison.

The global optimal fuel consumption calculated by DP is sent back to the upper level where the genetic algorithm continues the optimization process until a maximum number of generations is reached. A Pareto front of the fuel consumption versus the number of battery modules can be plotted for each architecture. This is presented in the following section.

\section{COMPARISON OF THE ARCHITECTURES}

In this section, the 3 proposed SPHEV architectures and the THS are compared. Before that, all architectures are optimized using the previously presented optimization process.

For the optimization, the vehicle characteristics and components used correspond to a middle class HEV and can be found in Table III. The reference maps of EM1, EM2 and ICE before sizing are shown in Fig. 7. The sized maps will be generated by multiplying the torque and losses by the scaling factor.

TABLE III

COMPONENT SPECIFICATIONS

\begin{tabular}{cc}
\hline \hline Component & Specification \\
\hline Engine & Gasoline, Atkinson \\
EM1 & Permanent Magnet Synchronous Motor \\
EM2 & Permanent Magnet Synchronous Motor \\
Battery & Nickel-metal hydride, (each module: 6.5 Ah \\
& capacity, 1kW maximum power) \\
Gearbox & 2-speed gearbox 98\% efficiency \\
Components Gear & parallel axis helical gears with a 98\% efficiency \\
Final Drive & $97 \%$ efficiency \\
Planetary Gear & $97 \%$ efficiency \\
Vehicle & middle class HEV \\
\end{tabular}



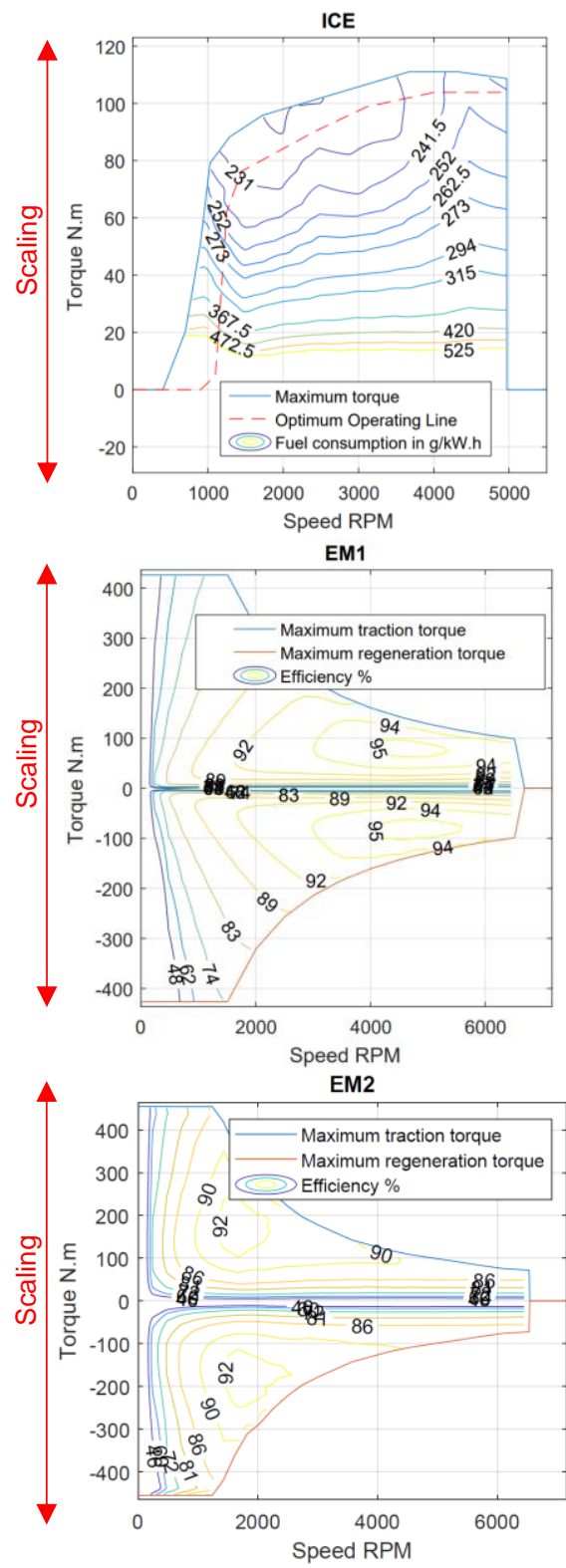

Fig. 7. EM1, EM2 and ICE maps before sizing

The fuel consumption objective function (FCons) is evaluated in mixed driving condition. FCons is computed as a weighted average of the fuel consumption in charge sustaining mode in urban, rural road and highway conditions. The ARTEMIS European driving cycles [32] are used to simulate these three conditions and the control is optimized on each of them.

$$
\begin{gathered}
\text { FCons }=\alpha \cdot F \text { Cons }_{\text {urban }}+\beta \cdot F \text { Cons }_{\text {rural }} \\
+\gamma \cdot F \text { Cons }_{\text {highway }}
\end{gathered}
$$

Where the $\alpha, \beta$ and $\gamma$ are coefficients calculated from the mean traveled distance by the French population in urban, rural road and highway conditions. These values are respectively 0.4 , 0.3 and 0.3 [33].

The Pareto fronts obtained at the end of 1000 iterations with a population size of 100 are presented in Fig. 8 .

The Pareto fronts shows that THS has globally a better fuel consumption than SPHEV 1. This confirms the results found in [6] and can be explained by the lack of speed degree of freedom (DoF) in SPHEV 1 and the increased usage of the series mode.

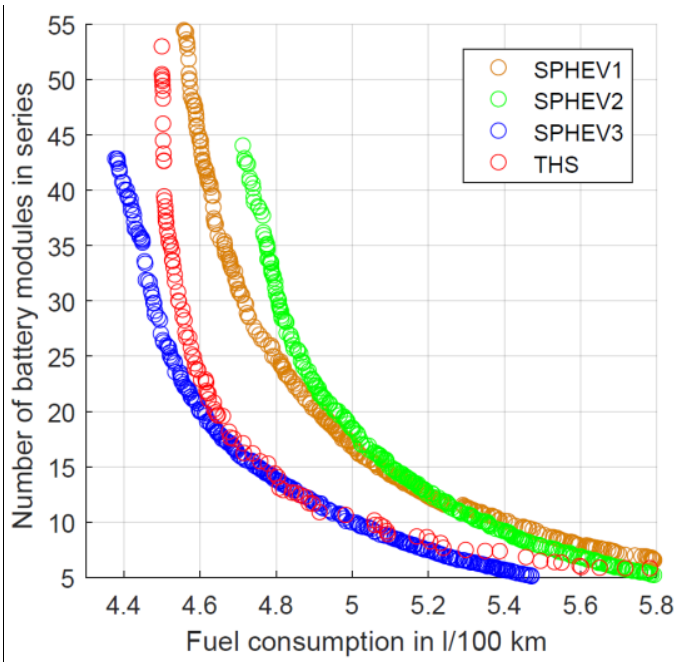

Fig. 8. The optimization Pareto fronts

SPHEV 2 happens to be less efficient than SPHEV 1. The reason behind the gears addition in SPHEV 2 was to try to move the operating points of the system to better efficiency areas, and to allow the parallel mode to be used more often. The effect of this probable improvement seems to be less than the effect of the deterioration in the power paths efficiencies

(due to gear losses), which results in a higher fuel consumption for the SPHEV 2 powertrain. This result is highly dependent on the gears efficiency which was chosen to be here $98 \%$ for each added gear.

SPHEV 3 has comparable fuel consumption to THS (see section $\mathrm{V}$ ). Thanks to the addition of the 2-speed gearbox, the improvements (caused by a more usage of the parallel mode (Table IV) are now more important than the deterioration in the power paths efficiencies. More details about this point can be found in [20].

The results of the optimization of all the architectures will be presented and elaborated in section $\mathrm{V}$.

\section{SENSITIVITY ANALYSIS}

In order to understand the influence of the gears addition on the fuel consumption, a sensitivity study is conducted in this section on SPHEV 2 sizing variables. The final target is to identify the improvements that can be done on this architecture and to finally propose a better version of it named SPHEV 2'.

In the context of a system model optimization, sensitivity analysis refers to understanding the influence of the system 
optimization parameters on the optimization objective function. Two approaches exist, local and global. While the local sensitivity explores only a small fraction of the design space, the global sensitivity uses a set of samples representative of the entire design space [34]. The set of samples is chosen by techniques like the Monte Carlo and Design of Experiments (DOE) [35].

The global approach is selected in this work. The calculation is done using the linear regression. Monte Carlo method is used for the choice of samples. It generated 6561 sets of sizing to be evaluated. The performance constraints are checked for all those combinations, but the fuel consumption is calculated only for the feasible combinations (842 out of 6561). Linear Regression's coefficients are finally calculated. They are shown in Fig. 9. A negative sensitivity is found when the variable and the fuel consumption have different sign of variation.

The arrows in Fig. 9 emphasize the difference in the sign of the gears sensitivity. It can be seen that the sensitivities of the Final Drive Ratio, the Gear for EM1 and the Gear for EM2 have all the same sign. However, the sensitivity of the Gear for ICE has a different sign.

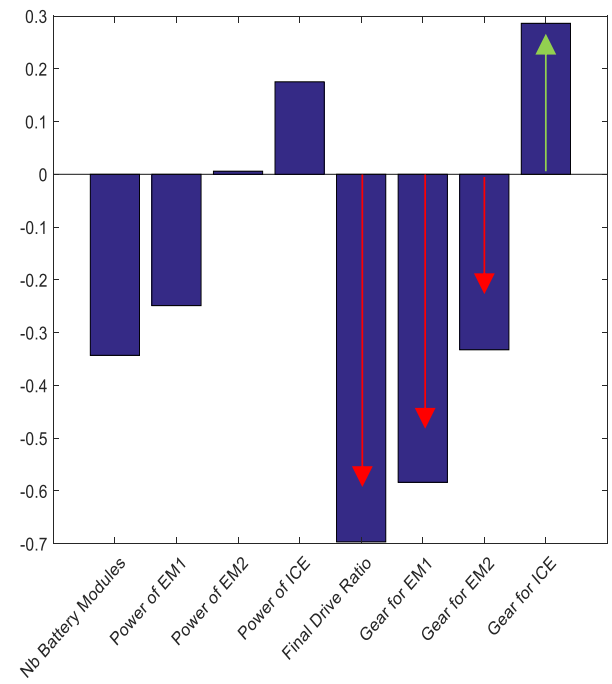

Fig. 9. Global sensitivity results for SPHEV 2 architecture

This means that increasing the Final Drive Ratio, or the Gear for EM1 or the Gear for EM2 will decrease the fuel consumption. From here, it can be suggested to combine those 3 variables in 1 variable that touches all the components affected by the 3 variables. This variable can be the Final Drive Ratio that actually affects the speed and torque of all the components. However, the Gear for ICE should be kept because its sensitivity is in contradiction with the Final Drive Ratio. Based on this, a new architecture is therefore proposed in the following section.

\section{NEW PROPOSED ARCHITECTURE}

Based on the understanding of the global sensitivities of the SPHEV 2 gears, a new simplified architecture SPHEV 2' is proposed (Fig. 10). SPHEV 2 ' is achieved by removing 2 gears from SPHEV 2. This should solve a main problem in SPHEV 2: the losses in the gears.

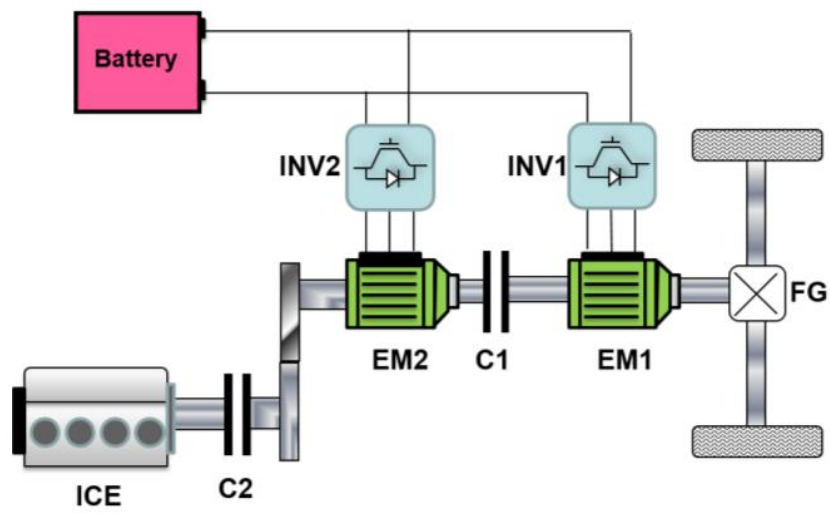

Fig. 10. The new proposed architecture SPHEV 2'

SPHEV 2' is optimized using the same methodology previously presented. The results are shown in Fig. 11.

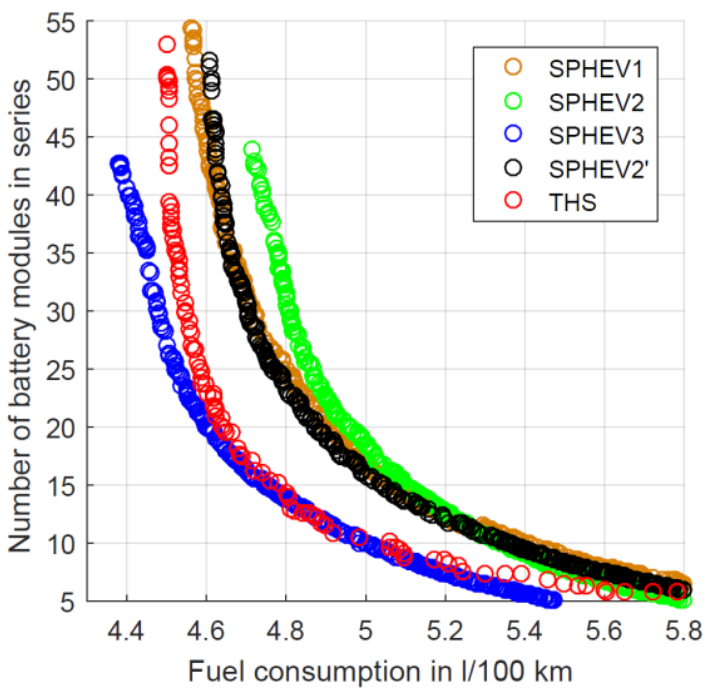

Fig. 11. Pareto fronts with SPHEV 2'

The improvements in fuel consumption for SPHEV 2' compared to SPHEV 2 are visible for a number of battery modules higher than 15. The removal of 2 gears from SPHEV 2 was favorable. However, the fuel consumption of SPHEV 2' remains close to the one of SPHEV 1 and is still higher than the fuel consumption of SPHEV 3 and THS. A compromise between the complexity of the architecture, the sizing and the efficiency should be always made. SPHEV 1 remains the simplest SPHEV architecture. However, to reach the efficiency of the power-split architecture, the addition of a 2 speed gearbox to the simple architecture seems necessary.

For a better understanding of those results, a closer look is made on the optimized powertrains corresponding to the Pareto points of 28 battery modules. Table IV presents for each architecture the distribution of the traction energy between the series path and the parallel path. The calculation is done for 
mixed driving conditions. A low usage of the series path is seen for SPHEV 3, compared to the other architectures. The 2-speed gearbox of SPHEV 3 allows the powertrain to use the parallel path more, while keeping the operating points of the components in relatively good efficiency zones. This is why it is found to be the most efficient.

TABLE IV

DISTRIBUTION OF THE TRACTION ENERGY*

BETWEEN SERIES AND PARALLEL PATHS FOR THE PARETO POINTS OF 28 BATTERY MODULES

\begin{tabular}{llcccc}
\hline \hline Path & THS & SPHEV1 & SPHEV2 & SPHEV3 & SPHEV2, \\
\hline Series & 547.3 & 1638.0 & 502.1 & 120.7 & 1836.3 \\
Parallel & 1926.6 & 875.7 & 1980.2 & 2359.6 & 664.5 \\
\hline
\end{tabular}

*Traction energy in Wh during hybrid modes for mixed driving conditions, calculated as: $\alpha$ *urban $+\beta$ *ural $+\gamma$ *highway, $\alpha=0.4, \beta=0.3, \gamma=0.3$

TABLE V

OPTIMAL SIZING FOR THE PARETO POINTS OF 28 BATTERY MODULES

\begin{tabular}{cccccc}
\hline \hline & THS & $\begin{array}{c}\text { SPHEV } \\
\mathbf{1}\end{array}$ & $\begin{array}{c}\text { SPHEV } \\
\mathbf{2}\end{array}$ & $\begin{array}{c}\text { SPHEV } \\
\mathbf{3}\end{array}$ & $\begin{array}{c}\text { SPHEV } \\
\mathbf{2}\end{array}$ \\
\hline $\begin{array}{c}\text { Power EM1 } \\
\text { (kW) }\end{array}$ & 58 & 84.1 & 68 & 59.3 & 85 \\
$\begin{array}{c}\text { Power EM2 } \\
\text { (kW) }\end{array}$ & 44.6 & 73.5 & 55.6 & 54.3 & 54.7 \\
Power ICE & 47.9 & 59.9 & 48.3 & 52.1 & 56 \\
(kW) & & & & & \\
PG & 1.5 & - & - & - & - \\
FG & 4.11 & 4.15 & 2.2 & 2.27 & 4.01 \\
G1 & - & - & 1.94 & 1.6 & - \\
G2 & - & - & 1.28 & 0.51 & - \\
G3 & - & - & 1.4 & - & 1.39 \\
GB 1st & - & - & - & 2.3 & - \\
GB 2nd & - & - & - & 1.06 & - \\
& & & & & \\
\hline
\end{tabular}

TABLE VI

FUEL CONSUMPTION (L/100KM)

\begin{tabular}{ccccc}
\hline \hline & Urban & Rural & Highway & Mixed \\
\hline SPHEV 1 & 4.45 & 4.02 & 5.85 & 4.74 \\
SPHEV 2 & 4.47 & 3.97 & 6.15 & 4.82 \\
SPHEV 3 & 4.15 & 3.82 & 5.63 & 4.50 \\
SPHEV 2 & 4.31 & 4.06 & 5.93 & 4.72 \\
THS & 4.47 & 3.70 & 5.54 & 4.56 \\
\hline
\end{tabular}

The powertrains optimal sizing is shown in Table $\mathrm{V}$ and their fuel consumption in Table VI. An oversizing of all the components is detected for SPHEV 1 and is linked to its high usage of the series mode (Table IV) where all the power going to the wheels is obliged to take one path instead of two (the case in parallel mode).

This explains also its high fuel consumption. With the addition of 3 gears, SPHEV 2 solves this oversizing problem and reduces the series mode but results in higher fuel consumption than SPHEV 1 . If only 1 of those 3 gears is added to SPHEV1 (case of SPHEV 2'), a downsizing of EM2 is achieved and the fuel consumption is slightly improved.
A difference is noted in the optimal gear ratios of SPHEV 2 and SPHEV 2'. The total ratio for the ICE is highly impacted $(1.4 * 2.2$ vs. $1.39 * 4.01)$. This should be explained by the ratio of EM1 which remains more or less constant $(1.94 * 2.2$ vs. 4.01).

More reduction in sizing can be achieved by SPHEV 3 which also has the least fuel consumption. It is found in [20] that this is due to the urban driving, where $59 \%$ of the traction energy in hybrid mode was transferred to the wheels using the series path in THS, compared to only 9.5\% in SPHEV 3. More details can be found in [20]. It should be re-mentioned that the sizing here was optimized for mixed driving conditions and that the 2speed gearbox efficiency is considered to be $98 \%$.

\section{CONCLUSION}

The design of (P)HEV powertrains is a complex task that involve an optimization on 3 levels: Architecture, Components technology \& Sizing, and Control. This paper is part of a global work that is trying to search the Architecture design space in the aim of discovering new efficient hybrid architectures with simple transmissions. The searching process is done in a nonautomatic way in this paper: the work starts from the simplest series parallel architecture that can be realized. Then, knowing this architecture's weak points, 2 other variants are proposed and studied. All architectures are optimized using a sizing and control bi-level optimization methodology. A genetic algorithm is used for the sizing, while the dynamic programming is used for the control and guarantees the calculation of the global optimal fuel consumption of each sizing candidate. The variant with a gearbox showed good improvements and a potential of fuel saving close to the THS architecture. The variant with 3 added gears showed however a decrease in efficiency. A global sensitivity is therefore performed on this latter architecture and an elimination of 2 gears is suggested. A new architecture is proposed and assessed. The removal of the gears was beneficial, but the architecture remains less efficient than the variant with a gearbox. In future work, the Architecture exploration and assessment will be automatized. The authors are working on developing a tool that automatically generates the architectures and automatically filter and assess them. In this tool the synchronizers and gears can be placed anywhere between the components, allowing the emergence of non-conventional transmissions. Future works will also include additional aspects of the powertrain in this assessment (compactness, weight, cost, life cycle considerations,...).

\section{REFERENCES}

[1] Groupe PSA, "Intelligent technologies for plug-in vehicles," Innovation Day 2016, pp. 1-10, 2016.

[2] Renault-Nissan-Mitsubishi, "Alliance 2022: New plan targets annual synergies of $€ 10$ billion and forecasts unit sales of 14 million \& combined revenues of \$240 billion," pp. 1-4, 2017.

[3] Volkswagen, "The Volkswagen Group launches the most comprehensive electrification initiative in the automotive industry with 'Roadmap E,"” Volkswagen Gr. Media Serv., no. 308, pp. 1-4, 2017.

[4] European Comission, "Europe accelerates the transition to clean mobility: Co-legislators agree on strong rules for the modernisation 
of the mobility sector," 2018. [Online]. Available:

https://ec.europa.eu/clima/news/europe-accelerates-transition-cleanmobility-co-legislators-agree-strong-rules-modernisation_en. [Accessed: 15-Jan-2019].

[5] C. C. Chan, A. Bouscayrol, and K. Chen, "Electric, hybrid, and fuelcell vehicles: Architectures and modeling," IEEE Trans. Veh. Technol., vol. 59, no. 2, pp. 589-598, 2010.

[6] E. Silvas, T. Hofman, N. Murgovski, P. Etman, and M. Steinbuch, "Review of Optimization Strategies for System-Level Design in Hybrid Electric Vehicles," IEEE Trans. Veh. Technol., vol. 66, no. 1, pp. 57-70, 2017.

[7] W. van Harselaar, T. Hofman, and M. Brouwer, "Automated Dynamic Modeling of Arbitrary Hybrid and Electric Drivetrain Topologies," IEEE Trans. Veh. Technol., vol. 67, no. 8, pp. 69216934, 2018.

[8] T. Hofman, S. Ebbesen, and L. Guzzella, "Topology Optimization for Hybrid Electric Vehicles With Automated Transmissions," IEEE Trans. Veh. Technol., vol. 61, no. 6, pp. 2442-2451, 2012.

[9] X. Zhang, C.-T. Li, D. Kum, and H. Peng, "Prius(+) and Volt(-): Configuration Analysis of Power-Split Hybrid Vehicles With a Single Planetary Gear," IEEE Trans. Veh. Technol., vol. 61, no. 8, pp. 3544-3552, 2012.

[10] E. Silvas, T. Hofman, A. Serebrenik, and M. Steinbuch, "Functional and Cost-Based Automatic Generator for Hybrid Vehicles Topologies," IEEE/ASME Trans. Mechatronics, no. iv, pp. 1-11, 2015.

[11] J. Wijkniet and T. Hofman, "Modified Computational Design Synthesis Using Simulation-Based Evaluation and Constraint Consistency for Vehicle Powertrain Systems," IEEE Trans. Veh. Technol., vol. 67, no. 9, pp. 8065-8076, 2018.

[12] X. Zhang, S. E. Li, H. Peng, and J. Sun, "Design of Multimode Power-Split Hybrid Vehicles - A Case Study on the Voltec Powertrain System," IEEE Trans. Veh. Technol., vol. 65, no. 6, pp. 4790-4801, 2016.

[13] C. C. Chan, "The state of the art of electric, hybrid, and fuel cell vehicles," Proc. IEEE, vol. 95, no. 4, pp. 704-718, 2007.

[14] K. Muta, M. Yamazaki, and J. Tokieda, "Development of newgeneration hybrid system THS II-Drastic improvement of power performance and fuel economy," 2004.

[15] U. D. Grebe and L. T. Nitz, "Voltec - The Propulsion System for Chevrolet Volt and Opel Ampera," MTZ worldwide, vol. 72, no. 5, Springer Automotive Media, pp. 4-11, 15-May-2011.

[16] E. Vinot, "Comparison of different power-split hybrid architectures using a global optimization design method.," Int. J. Electr. Hybrid Veh., vol. 8, no. 3, pp. 225-241, 2016.

[17] E. Vinot, V. Reinbold, and R. Trigui, "Global Optimized Design of an Electric Variable Transmission for HEVs," IEEE Trans. Veh. Technol., vol. 65, no. 8, pp. 6794-6798, 2016.

[18] N. Higuchi and H. Shimada, "Efficiency enhancement of a new two-motor hybrid system," World Electr. Veh. J., vol. 6, no. 2, pp. 325-335, 2013.

[19] R. Trigui, E. Vinot, and B. Jeanneret, "Backward Modeling and Energy Management Optimization of a Two Clutches SeriesParallel HEV for Efficiency Assessment," in Power plant and power system control symposium IFAC PPPSC), 2012, 2012.

[20] B. Kabalan, E. Vinot, Y. Cheng, R. Trigui, and C. Dumand, "Improvement of a Series-Parallel Hybrid Electric Vehicle Architecture," in 2017 IEEE Vehicle Power and Propulsion Conference (VPPC), 2017, pp. 1-6.

[21] S. Washino, T. Saito, and Y. Jia, "New 3 Mode Hybrid System Concept," 24th Aachen Colloq. Automob. Engine Technol. 2015, 2015.

[22] E. Vinot, J. Scordia, R. Trigui, B. Jeanneret, and F. Badin, "Model simulation, validation and case study of the 2004 THS of Toyota Prius," Int. J. Veh. Syst. Model. Test., vol. 3, no. 3, pp. 139-167, 2008.

[23] V. Reinbold, E. Vinot, L. Garbuio, and L. Gerbaud, "Optimal sizing of an electrical machine using a magnetic circuit model: application to a hybrid electrical vehicle," IET Electr. Syst. Transp., vol. 6, no. 1, pp. 27-33, 2016.

[24] ORNL, "Evaluation of 2004 Toyota Prius hybrid electric drive system," 2006.

[25] M. Le Guyadec, L. Gerbaud, E. Vinot, and B. Delinchant, "Sensitivity analysis using Sobol indices for the thermal modelling of an electrical machine for sizing by optimization," COMPEL - Int.
J. Comput. Math. Electr. Electron. Eng., vol. 38, 2019.

[26] B. Kabalan, Y. Cheng, E. Vinot, C. Dumand, R. Trigui, and W. Bou Nader, "Optimal Design and Sizing of Through-The-Road Hybrid Vehicle Powertrain," in SIA Powertrain 2018, 2018, pp. 1-7.

[27] K. Deb, A. Pratap, S. Agarwal, and T. Meyarivan, "A Fast and Elitist Multiobjective Genetic Algorithm : NSGA-II," IEEE Trans. Evol. Comput., vol. 6, no. 2, pp. 182-197, 2002.

[28] E. Vinot, R. Trigui, Y. Cheng, C. Espanet, A. Bouscayrol, and V. Reinbold, "Improvement of an EVT-based HEV using dynamic programming," IEEE Trans. Veh. Technol., vol. 63, no. 1, pp. 4050, 2014.

[29] R. E. Bellman, Dynamic Programming. Princeton University Press, 1957.

[30] E. Vinot, "Time reduction of the dynamic programming computation in the case of hybrid vehicle," in Optimization \& Inverse Problems in Electromagnetism (OIPE), 2014, 2014.

[31] O. Sundstrom, D. Ambuhl, and L. Guzzella, "On implementation of dynamic programming for optimal control problems with final state constraints," Oil Gas Sci. Technol. l'Institut Fran\{̧́\}̧ais du P\{é\}trole, vol. 65, no. 1, pp. 91-102, 2010.

[32] M. André, "The ARTEMIS European driving cycles for measuring car pollutant emissions," Sci. Total Environ., vol. 334-335, pp. 7384, Dec. 2004.

[33] Eurostat, "Eurostat statistic on population displacement, http://epp.eurostat.ec.europa.eu/portal/page/portal/transport/data/dat abase

http://appsso.eurostat.ec.europa.eu/nui/show.do?dataset=road_tf_roa d\&lang=fr."

[34] A. Saltelli et al., Global Sensitivity Analysis. 2008.

[35] J. Goupy and L. Creighton, Introduction aux plans d'expériences. 2006.

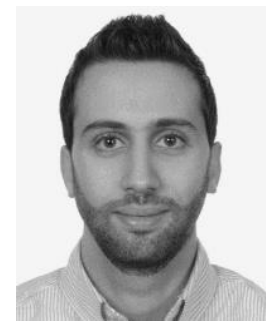

B. Kabalan received his Bachelor of Engineering B.E. in Mechanical Engineering from the Lebanese American University, Byblos, Lebanon in 2015. He received a Master of Science M.S. degree in Powertrain Engineering from IFP School, Rueil-Malmaison, France in 2017.

$\mathrm{He}$ is currently a $\mathrm{PhD}$ candidate in the Advanced Research Department of Groupe PSA. His PhD is taking place in the French Institute of Science and Technology for Transport, Development and Networks (IFSTTAR). His work is focused on developing an optimal methodology for the design of hybrid electric vehicle powertrains.

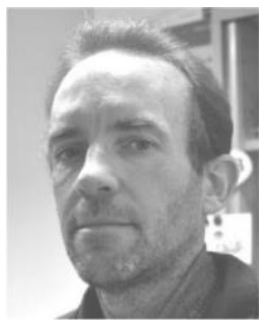

E. Vinot received his Engineering degree of Ecole Nationale Supérieure d'Electricité de Grenoble (1997), the M.S. degree in Electrical Engineering from the Laval University, Québec, Canada (1998) and the $\mathrm{PhD}$ degree from the Electrotechnic Laboratory of the National Polytechnique Institute of Grenoble (INPG), France, in 2000.

Since 2005, he is working in the French Institute of Science and Technology for Transport, Development and Networks (IFSTTAR) in the Eco7 team. His main interests are systemic model of vehicle and components, system management optimization, and system and electrical machine design. 


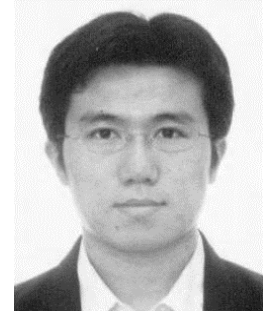

Y. Cheng received the B.S., M.Sc., and $\mathrm{Ph} . \mathrm{D}$. degrees from Harbin Institute of Technology, Harbin, China, in 2002, 2004, and 2009 , respectively, all in electrical engineering.

In 2012, he joined Groupe PSA, Paris, France, where he is responsible for the research on novel hybrid powertrains, novel electromagnetic converters and associated optimization and simulation tools. His research interests include the design and control of electric machines, modeling, control and optimization of electric vehicles (EVs) and hybrid EVs (HEVs).

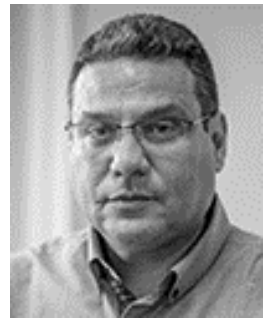

R. Trigui was born in Sfax, Tunisia, in 1969. He received the electrical engineering degree from the National High School of Electrical and Mechanical Engineering of Nancy, France, in 1993 and the $\mathrm{PhD}$ degree in Electrical Engineering in 1997 from the Polytechnic National Institute of Lorraine. He then worked for one year as an associate researcher at PSA Peugeot Citroën.

Since 1998, he is full researcher (senior since 2012) in the French Institute of Science and Technology for Transport, Development and Networks (IFSTTAR, former INRETS) in the field of modelling and energy management of electric and hybrid vehicles. From 2008 to 2015 he has been leading the Electric and Hybrid Vehicles team of the Transport and Environment Laboratory of IFSTTAR. He is now deputy head of AME department of IFSTTAR. He is also currently member of the French MEGEVH network. He was co-chair of IEEE VPPC 2010.

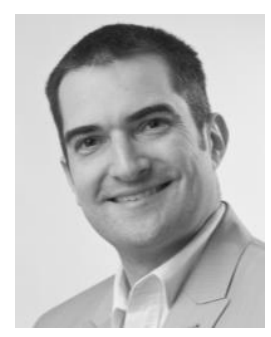

C. Dumand received his Engineering degree of Polytech'Orléans (2002) and the $\mathrm{PhD}$ degree from ENSMA of Poitiers, France, in 2005.

Currently, he is team leader in the Advanced Research Department of Groupe PSA. His team is in charge of advanced research in powertrain, new energy converter and energy storage technologies, new energy pathways and advanced Computer Aided Design using Artificial Intelligence and automatic optimization.

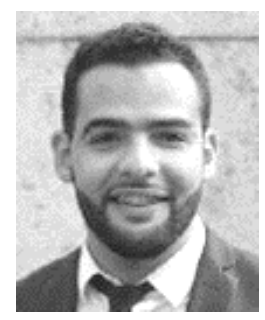

T. El Hajji received his Master of Engineering in Electrical Engineering and Automation from ENSEEIHT, Toulouse, France, in 2018. He received a Master of Research in Automotive Electrification and Propulsion from Ecole Normale Supérieure Paris-Saclay, Cachan, France in 2018.

$\mathrm{He}$ is currently a $\mathrm{PhD}$ candidate at Groupe PSA. His PhD is taking place in laboratory SATIE. His work is focused on high speed electrical machines for electric vehicles. 